\title{
Application of a Mapping Function to Estimate Utilities for Ragweed Allergy Immunotherapy Trials
}

\author{
Katherine Dick ${ }^{1}$. Andrew Briggs ${ }^{1,2} \cdot$ Henrik Brandi $^{3}$
}

Published online: 9 March 2020

(c) The Author(s) 2020

\begin{abstract}
Background Ragweed pollen sensitivity is a common cause of allergic rhinitis (AR) worldwide. AR symptoms include itchy and runny eyes, sneezing, blocked nose, impaired sleep and social and emotional problems, which can have a significant impact on quality of life.

Objective The objective of this analysis was to estimate utilities for two pooled standardised quality (SQ) ragweed sublingual immunotherapy (SLIT) tablet trials by applying a previously developed mapping algorithm. This study validated the algorithm and extended its application to ragweed seasonal allergy trials. The mapping algorithm relates disease-specific quality-of-life scores to preference-based utilities that may be used to calculate quality-adjusted life-years (QALYs) in cost-effectiveness studies. Methods A mapping algorithm based on a grass pollen allergy immunotherapy trial, GT-08 (EudraCT no. 2004-000083-27) was applied to pooled data from two ragweed pollen immunotherapy trials, P05233 (EudraCT 2008-003863-38) and P05234 (EudraCT 2008-003864-20) to generate EuroQoL 5-Dimensions, 3-Levels (EQ-5D-3L) utilities from Rhinoconjunctivitis Quality of Life Questionnaire (RQLQ) data.

Results The mean utility difference between the SQ ragweed SLIT tablet and placebo was 0.025 [95\% confidence interval (CI) 0.011-0.038]. The SQ ragweed SLIT tablet showed an incremental quality-adjusted life-days (QALDs) benefit of 1.900 (95\% CI $0.835-2.916)$ over 75 days.

Conclusions Application of a previously developed mapping function allowed for the calculation of QALDs associated with the SQ ragweed SLIT tablet. The results showed a QALD benefit of the SQ ragweed SLIT tablet in P05233 and P05234 trials in the treatment of ragweed pollen-induced AR.
\end{abstract}

\section{Key Points for Decision Makers}

This study validated a Rhinoconjunctivitis Quality of Life Questionnaire (RQLQ) mapping function and extended its application to ragweed seasonal allergy trials.

The standardised quality (SQ) ragweed SLIT tablet provides quality-of-life benefits to patients with ragweed pollen-induced allergic rhinitis.

Katherine Dick

Katherine.Dick@AvalonEcon.com

1 Health Economist, Avalon Health Economics, 26 Washington Street, Floor 2, Morristown, NJ 07960, USA

2 London School of Hygiene and Tropical Medicine, London, UK

3 ALK, Hørsholm, Denmark

\section{Introduction}

Ragweed is an invasive flowering plant that originated in North America and spread worldwide. Ragweed sensitivity affects $15-26 \%$ of the population in the USA. In Europe, clinically relevant ragweed pollen sensitisation has a prevalence of $11 \%$ among referrals to allergy specialists and is a common cause of allergic rhinitis (AR) and asthma [1-4]. The symptoms of AR include itchy eyes, runny eyes, sneezing, blocked nose and impaired sleep, as well as social and emotional problems [5]. These symptoms significantly impact on patient quality of life $[1,6,7]$. Patients often require additional general practice services and medication, which can be a financial burden [6-8].

AR may be treated by allergen avoidance, symptomrelieving medications and allergy immunotherapy (AIT). Symptomatic medications include antihistamines, intranasal glucocorticoids and leukotriene receptor antagonists. However, symptomatic medications do not target the underlying disease process causing the allergy, so 
treatment must be administered repeatedly for as long as patients experience symptoms, which can be for life [9]. AIT is a disease-modifying therapy that induces a long-term immune tolerance that benefits quality of life for years after treatment discontinuation [1, 10]. AIT contains allergen extracts from the target allergen and may be administered subcutaneously or sublingually [1, $11,12]$. The standardised quality (SQ) ragweed sublingual immunotherapy (SLIT) tablet is a convenient and evidence-based alternative to subcutaneous AIT, as it can be administered at home and has demonstrated efficacy in the treatment of ragweed pollen-induced AR. The at-home administration makes SLIT tablets a cost-saving alternative for the healthcare sector [13].

The effect of AR on quality of life may be assessed using preference-based measures (PBMs) or disease-specific measures. Generic PBMs assess general quality of life with standardised dimensions broad enough to capture quality-oflife differences in most disease areas. PBM responses may be used to generate health state utilities, which are relative preference weights for different health states measured on a cardinal scale and may be used to calculate quality-adjusted life-years (QALYs), a common outcome in cost-effectiveness studies $[14,15]$. Disease-specific measures of quality of life such as the Rhinoconjunctivitis Quality of Life Questionnaire (RQLQ) have the advantage of greater sensitivity to condition-specific symptoms but may not be used to calculate QALYs [14-17].

When PBMs are not used in a clinical trial, it is possible to 'map' disease-specific quality-of-life scores to preference-based utilities that may be used to calculate QALYs in cost-effectiveness studies $[16,17]$. In a previous study, we developed a mapping algorithm based on a grass pollen immunotherapy trial and applied the algorithm to a tree pollen immunotherapy trial in order to estimate utilities and quality-adjusted life-days (QALDs) [18]. In this study, we applied the algorithm to data pooled from two SQ ragweed SLIT tablet trials to estimate utilities and QALDs because PBM data were not collected.

\section{Methods}

\subsection{Clinical Trials}

The mapping algorithm was developed based on a grass pollen allergy immunotherapy trial, GT-08 (EudraCT no. 2004000083-27) [19]. This trial was a randomised, double-blind, placebo-controlled, 5-year phase III trial designed to assess the efficacy and safety of the SQ grass SLIT tablet to treat AR in subjects with seasonal grass pollen allergy $[9,18]$. The grass pollen season was defined between the first of three consecutive days and the last day of the last occurrence of three consecutive days with pollen count $\geq 10$ grains $/ \mathrm{m}^{3}$. In total, 634 adults with a clinical history of grass polleninduced AR with moderate to severe symptoms despite pharmacotherapy use were randomised to active treatment plus pharmacotherapy or placebo plus pharmacotherapy. Subjects were asked to complete a daily record of AR symptoms and medication use in an electronic diary. The six recorded AR symptoms were runny nose, blocked nose, sneezing, itchy nose, itchy eyes and watery eyes. The three recorded asthma symptoms were cough, wheeze and shortness of breath. Subjects scored these symptoms on a scale from zero to three $(0=$ none, $1=$ mild, $2=$ moderate, $3=$ severe $)$. The AR symptom scores were added to generate the 'daily symptom score', and the asthma scores were added to create the 'asthma symptom score'. Daily medication use was measured on a scale from 0 to 36 according to the type and dosage of medication used [19]. Throughout the trial, subjects had access to symptom-relieving medications, including desloratadine, olopatadine, budesonide and prednisone. Subjects were also asked to complete two quality-of-life instruments every week: the three-level EuroQoL 5-Dimensions (EQ-5D-3L) and the RQLQ [20].

The EQ-5D is a common PBM recommended by the UK National Institute for Health and Care Excellence for estimation of health state utilities. It measures quality of life in five dimensions: mobility, self-care, usual activities, pain/discomfort and anxiety/depression [21]. This study used the EQ-5D-3L instrument, and index values were derived from the UK value set [22]. The RQLQ is a disease-specific questionnaire consisting of 28 questions in seven domains: activity limitation, sleep problems, nose symptoms, eye symptoms, non-nose/eye symptoms, practical problems and emotional function. Subjects rated their health in these dimensions on seven levels $(0=$ no impairment, $6=$ severe impairment) [23].

In this study, we applied the previously developed mapping algorithm to pooled data from two SQ ragweed SLIT tablet trials, P05233 and P05234, to calculate utilities and QALDs. The SQ ragweed SLIT tablet trials were pooled to increase the sample size and statistical power of the data. Pooling the trials was appropriate in this case because the trials were identical in terms of active treatment, population, treatment period, data collection and outcomes of interest. The primary difference between the studies was the location of the treatment sites, and the associated difference in pollen counts. However, the average pollen counts were similar between the two trials. The mean pollen count during the P05233 trial was 127 grains $/ \mathrm{m}^{3}$, and the average pollen count during the $\mathrm{P} 05234$ trial was 122 grains $/ \mathrm{m}^{3}$.

The P05233 trial evaluated the safety and efficacy of the SQ ragweed SLIT tablet (SCH 39641) compared with placebo for the treatment of AR in subjects with seasonal 
ragweed allergies [24]. Subjects received either placebo $(n=188), 6$ Amb a $1-\mathrm{U}$ ragweed SLIT tablet $(n=190)$, or the marketed dose of $12 \mathrm{Amb}$ a 1-U ragweed SLIT tablet $(n=187)$. Subjects were treated for 52 weeks, beginning 16 weeks before the start of the ragweed season (RS). During the RS, patients were provided with symptom-relieving medications used in a stepwise manner according to symptom severity, including loratadine, olopatadine, mometasone and prednisone. The trial was initiated at 67 sites in the USA and at 13 sites in Canada. Similar to the GT-08 trial, subjects were asked to record daily symptoms and medication use in an electronic diary, assessed on the same scale as during the GT-08 trial. The RS was defined between the first of 3 consecutive days in which the ragweed pollen count was above the threshold of 10 grains $/ \mathrm{m}^{3}$ and the last of three consecutive days in which the pollen count remained above the threshold.

The P05234 trial evaluated the efficacy and safety of the same SQ ragweed SLIT tablet and included an extra dosage arm [25]. In total, 784 subjects were randomised to placebo $(n=198)$ or one of three treatment groups: $1.5 \mathrm{Amb}$ a $1-\mathrm{U}(n=197), 6 \mathrm{Amb}$ a $1-\mathrm{U}(n=195)$ or the marketed dose of 12 Amb a 1-U ragweed AIT $(n=194)$. The trial design for P05234 was the same as in P05233, including treatment period, pollen threshold, data collection and scoring. P05234 included 114 sites in the USA, Canada, Hungary, Ukraine and Russia. Table 1 presents the baseline characteristics for both trials.

\subsection{Mapping Algorithm}

The development of the two-part mapping algorithm from the weekly EQ-5D-3L data has been described in detail in the previous study [18]. The first part of the algorithm predicts the probability of (im)perfect health, and the second part predicts the disutility conditional on imperfect health. Covariates were chosen for inclusion in the model according to their expected clinical relevance and availability in both the GT-08 trial and the trial onto which the utilities were mapped. The final models were developed using longitudinal weekly EQ-5D-3L data and included the following covariates: RQLQ score, daily symptom score, daily medication score, sex and asthma symptom score. All covariates in the algorithm were also available in each of the SQ ragweed SLIT tablet trials. This model was applied to the pooled data, and utilities were predicted using the regression equation coefficients presented in Table 2.

The first stage of the model predicts the probability of perfect health. The coefficients in Table 2 are in terms of $\log$ odds, so, to calculate the probability of perfect health, $\mathrm{P}($ health), the inverse logit transformation was applied:
$P($ perfect health $)=\frac{e^{x \beta}}{1+e^{x \beta}}$,

for a linear predictor $x \beta$, where $x$ represents a vector of observed covariates for a given patient at a given time point, and $\beta$ represents the estimated coefficients from Table 2 such that:

$$
\begin{aligned}
x \beta= & 0.623 * \text { Male }-0.069 * \mathrm{DSS}-0.070 * \text { DMS } \\
& +0.010 *(\mathrm{DSS} \times \mathrm{DMS})-1.869 * \text { RQLQ score } \\
& +4.587 .
\end{aligned}
$$

For example, if a female $($ male $=0)$ subject reports a symptom score of 7, a medication score of 8, and an RQLQ score of 4.86, then the probability of perfect health on that day is 0.013 , which corresponds to a $1-0.013=0.987$ probability of imperfect health.

In the second stage of the model, EQ-5D-3L disutilities, $d$, were estimated from the coefficients of a linear mixed model and therefore predicted directly as:

$$
\begin{aligned}
d= & -0.003 * \text { DSS }-0.002 * \text { DMS } \\
& +0.0004 *(\mathrm{DSS} \times \mathrm{DMS}) \\
& +0.015 * \text { Asthma Symptom Score } \\
& +0.051 * \text { RQLQ Score }+0.141 .
\end{aligned}
$$

In the observation described above, the subject also reported an asthma symptom score of 0 , so the predicted disutility was 0.375 . The results of both stages were used to calculate utility conditional on imperfect health:

$u=1-P($ imperfect health $) * d=1-0.987 * 0.375=0.630$.

Predicted utilities were calculated for each day of the RS for each treatment arm. In this analysis, QALYs and utilities were analysed over the range of relative days with at least one EQ-5D-3L response in each treatment arm within the RS to accurately capture the utility difference during the RS. The difference in QALDs between treatment arms was calculated by multiplying the mean utility difference by the number of days over which the utilities were averaged. Only subjects at the marketed highest dosage level (12 Amb a 1-U) were included in this analysis. Days were counted relative to the first day of the pollen season, and day 0 of the analysis was the first day of the RS, which varied by geographic region of pollen exposure.

\section{Results}

The algorithm was applied to pooled SQ ragweed SLIT tablet trial data to predict EQ-5D-3L utilities. Figure 1 shows the predicted pooled mean utilities by treatment. The utilities are superimposed on daily pollen counts averaged across both 
Table 1 Baseline characteristics of SQ grass SLIT tablet and SQ ragweed SLIT tablet analytic sets

\begin{tabular}{|c|c|c|c|c|c|c|c|c|}
\hline \multirow[t]{2}{*}{ Characteristic } & \multicolumn{2}{|l|}{ GT-08 } & \multicolumn{2}{|l|}{ P05233 } & \multicolumn{2}{|l|}{ P05234 } & \multicolumn{2}{|c|}{ Pooled ragweed trials } \\
\hline & $\begin{array}{l}\text { Placebo } \\
(n=276)\end{array}$ & $\begin{array}{l}\text { SQ grass } \\
\text { SLIT tablet } \\
(n=277)\end{array}$ & $\begin{array}{l}\text { Placebo } \\
(n=184)\end{array}$ & $\begin{array}{l}\text { Ragweed } \\
\text { SLIT tablet } \\
12 \text { Amb a } 1-\mathrm{U} \\
(n=183)\end{array}$ & $\begin{array}{l}\text { Placebo } \\
(n=196)\end{array}$ & $\begin{array}{l}\text { Ragweed } \\
\text { SLIT tablet } \\
12 \text { Amb a } 1-\mathrm{U} \\
(n=191)\end{array}$ & $\begin{array}{l}\text { Placebo } \\
(n=380)\end{array}$ & $\begin{array}{l}\text { Ragweed } \\
\text { SLIT tablet } \\
12 \text { Amb a } 1-\mathrm{U} \\
(n=374)\end{array}$ \\
\hline \multicolumn{9}{|l|}{ Sex, $n(\%)$} \\
\hline Male & $167(61)$ & $164(59)$ & $93(51)$ & $75(41)$ & $100(51)$ & $102(53)$ & $193(51)$ & $177(47)$ \\
\hline Female & $109(39)$ & $113(41)$ & $91(49)$ & $108(59)$ & $96(49)$ & 89 (47) & $187(49)$ & $197(53)$ \\
\hline \multicolumn{9}{|l|}{ Age } \\
\hline Mean \pm SD & $34.3 \pm 10.1$ & $34.2 \pm 9.5$ & $36.0 \pm 9.2$ & $34.8 \pm 9.4$ & $36.7 \pm 8.5$ & $35.7 \pm 8.8$ & $36.3 \pm 8.9$ & $32.3 \pm 9.1$ \\
\hline $\begin{array}{l}\text { Median (Q1; } \\
\text { Q3) }\end{array}$ & $33(27 ; 40)$ & $33(27 ; 39)$ & $37(29 ; 44)$ & $36(27 ; 44)$ & $38(30 ; 44)$ & $37(29 ; 44)$ & $38(30 ; 44)$ & $36(28 ; 44)$ \\
\hline \multicolumn{9}{|c|}{ Rhinitis symptom score } \\
\hline Mean \pm SD & $2.8 \pm 3.4$ & $2.0 \pm 2.8$ & $4.2 \pm 4.0$ & $3.6 \pm 3.4$ & $3.6 \pm 3.8$ & $3.0 \pm 3.3$ & $3.4 \pm 3.9$ & $3.3 \pm 3.4$ \\
\hline $\begin{array}{l}\text { Median (Q1; } \\
\text { Q3) }\end{array}$ & $2(0 ; 5)$ & $0(0 ; 3)$ & $3(1 ; 6)$ & $3(1 ; 6)$ & $3(0 ; 6)$ & $2(0 ; 5)$ & $3(0 ; 6)$ & $2(0 ; 5)$ \\
\hline \multicolumn{9}{|c|}{ Medication score } \\
\hline Mean \pm SD & $2.1 \pm 4.0$ & $1.5 \pm 3.3$ & $1.5 \pm 3.8$ & $0.94 \pm 3.0$ & $1.8 \pm 4.2$ & $1.7 \pm 3.3$ & $1.7 \pm 4.0$ & $1.1 \pm 3.1$ \\
\hline $\begin{array}{l}\text { Median (Q1; } \\
\text { Q3) }\end{array}$ & $0(0 ; 3)$ & $0(0 ; 0)$ & $0(0 ; 0)$ & $0(0 ; 0)$ & $0(0 ; 0)$ & $0(0 ; 0)$ & $0(0 ; 0)$ & $0(0 ; 0)$ \\
\hline \multicolumn{9}{|c|}{ Asthma symptom score } \\
\hline Mean \pm SD & $0.3 \pm 0.9$ & $0.2 \pm 0.8$ & $0.47 \pm 1.2$ & $0.37 \pm 0.91$ & $0.4 \pm 1.1$ & $0.4 \pm 1.0$ & $0.4 \pm 1.1$ & $0.4 \pm 0.9$ \\
\hline $\begin{array}{l}\text { Median (Q1; } \\
\text { Q3) }\end{array}$ & $0(0 ; 0)$ & $0(0 ; 0)$ & $0(0 ; 0)$ & $0(0 ; 0)$ & $0(0 ; 0)$ & $0(0 ; 0)$ & $0(0 ; 0)$ & $0(0 ; 0)$ \\
\hline \multicolumn{9}{|c|}{ History of asthma, $n(\%)$} \\
\hline Yes & $33(12)$ & $43(15)$ & $43(23)$ & $42(23)$ & $32(16)$ & $36(19)$ & $75(20)$ & $78(21)$ \\
\hline No & $125(45)$ & $145(52)$ & $141(77)$ & $141(77)$ & $164(84)$ & $155(80)$ & $305(80)$ & $296(79)$ \\
\hline Missing & $118(43)$ & $89(32)$ & $0(0)$ & $0(0)$ & $0(0)$ & $0(0)$ & $0(0)$ & $0(0)$ \\
\hline \multicolumn{9}{|l|}{ RQLQ score } \\
\hline Mean $\pm S D$ & $0.91 \pm 1.0$ & $0.69 \pm 0.9$ & $1.4 \pm 1.3$ & $1.2 \pm 1.1$ & $1.1 \pm 1.2$ & $0.98 \pm 1.1$ & $1.3 \pm 1.2$ & $1.07 \pm 1.1$ \\
\hline $\begin{array}{l}\text { Median (Q1; } \\
\text { Q3) }\end{array}$ & $1(0 ; 1.1)$ & $0.61(1 ; 1)$ & $1.1(0.4 ; 2.2)$ & $0.89(0.3 ; 1.8)$ & $0.79(0.1 ; 1.8)$ & $0.64(0.1 ; 1.5)$ & $1.0(0.3 ; 2.0)$ & $\begin{array}{l}0.75(0.14 \\
1.64)\end{array}$ \\
\hline
\end{tabular}

$R Q L Q$ Rhinoconjunctivitis Quality of Life Questionnaire, $S D$ standard deviation, $S L I T$ sublingual immunotherapy, $S Q$ standardised quality

Table 2 Allergic rhinitis mapping function to EQ-5D-3L

\begin{tabular}{|c|c|c|c|c|}
\hline \multirow[t]{2}{*}{ Variable } & \multicolumn{2}{|l|}{ Stage 1} & \multicolumn{2}{|l|}{ Stage 2} \\
\hline & Coefficient & $p$ value & Coefficient & $p$ value \\
\hline Male & 0.623 & 0.009 & - & - \\
\hline Rhinitis symptom score & -0.069 & $<0.001$ & -0.003 & 0.011 \\
\hline Medication score & -0.070 & $<0.001$ & -0.002 & 0.089 \\
\hline $\begin{array}{l}\text { Interaction (rhinitis } \\
\text { symptoms and medi- } \\
\text { cation) }\end{array}$ & 0.010 & $<0.001$ & 0.0004 & 0.001 \\
\hline Asthma symptom score & - & - & 0.015 & $<0.001$ \\
\hline RQLQ score & -1.869 & $<0.001$ & 0.051 & $<0.001$ \\
\hline Intercept & 4.587 & $<0.001$ & 0.141 & $<0.001$ \\
\hline $\begin{array}{l}\text { Akaike information } \\
\text { criterion }\end{array}$ & 7712 & & -3487 & \\
\hline
\end{tabular}

$E Q-5 D-3 L$ three-level EuroQoL 5-Dimensions instrument, $R Q L Q$ Rhinoconjunctivitis Quality of Life Questionnaire trials. The figure shows a clear separation between treatment arms, a difference that is most pronounced at the peak of the pollen season.

The mean utility difference and QALDs were calculated between relative days 0 and 75 . At least one pollen region had a duration of 76 days, though many were shorter. This method ensured that all data points collected within the RS were considered in the calculation. The mean utility difference between the SQ ragweed SLIT tablet and placebo was 0.025 [95\% confidence interval (CI) 0.011-0.038]. QALDs were calculated by multiplying the difference in pooled mean utility by the length of the season of interest. The SQ ragweed SLIT tablet showed an incremental QALD benefit of 1.900 (95\% CI 0.835-2.916) (Table 3). 
Fig. 1 Pooled P05233 and P05234 - mean daily utilities and pollen counts

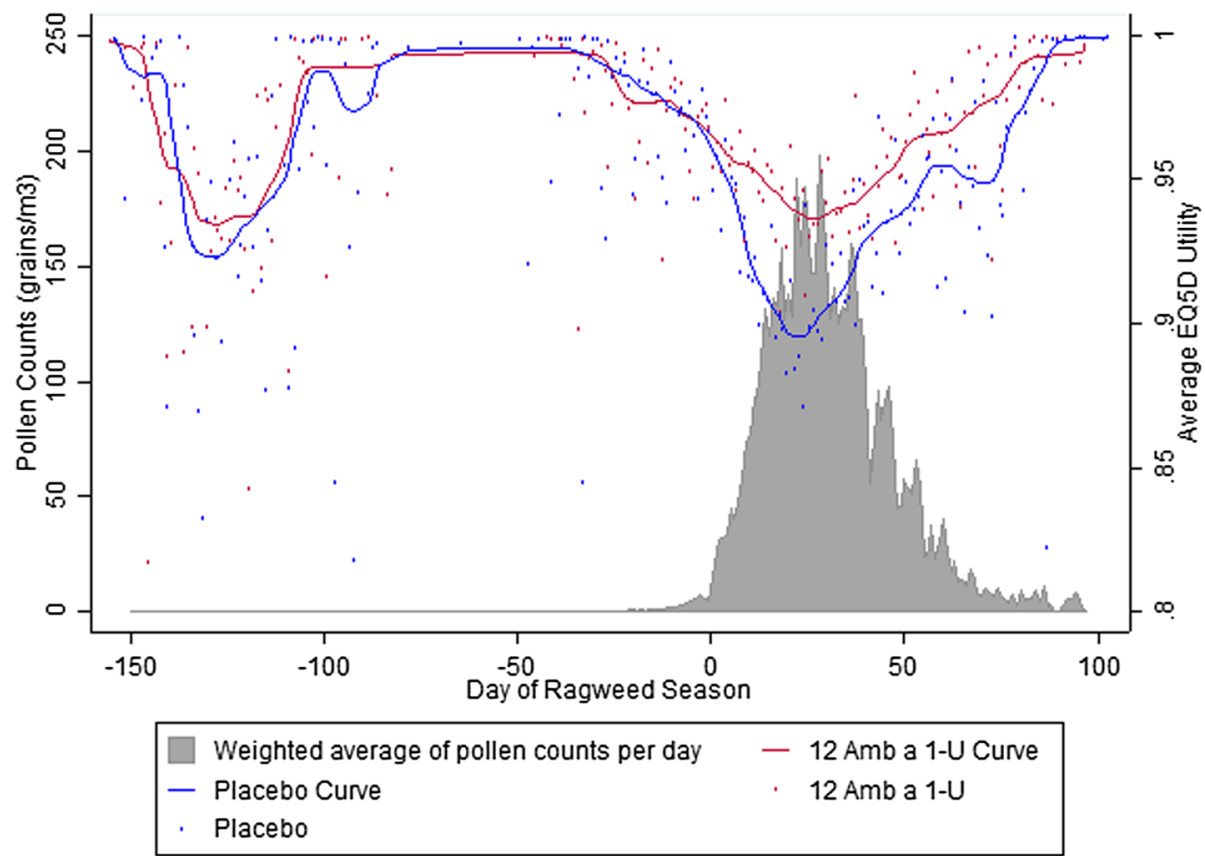

Table 3 Pooled utilities and QALDs (days 0-75)

\begin{tabular}{lll}
\hline Estimate & & SE (95\% CI) \\
\hline 12 Amb a 1-U average utility & 0.949 & \\
Placebo average utility & 0.924 & \\
Mean utility difference & 0.025 & $0.007(0.011-0.038)$ \\
QALDs & 1.900 & $0.531(0.835-2.916)$ \\
\hline
\end{tabular}

$C I$ confidence interval, $Q A L D s$ quality-adjusted life-days, $S E$ standard error

\section{Discussion}

This study provides evidence that immunotherapy improves quality of life in patients with seasonal ragweed allergies and generates utilities for use in cost-effectiveness studies. Although mapping functions exist for chronic rhinosinusitis and asthma condition-specific measures, the algorithm developed in the previous study is the first to map RQLQ onto EQ-5D-3L utilities in AR [26, 27]. The results of the current study validate the previously developed algorithm, suggesting that the mapping algorithm may be applied to SQ ragweed SLIT tablet trials in addition to the SQ tree SLIT tablet trial in the previous study.

A key limitation in this analysis is the assumption that grass pollen allergy and ragweed pollen allergy have the same relationship with EQ-5D-3L utilities and other key covariates in the mapping algorithm. This assumption is supported by the fact that both grass and ragweed pollen are seasonal allergies and induce similar AR symptoms, such as itchy eyes, runny eyes, sneezing and blocked nose [7, $25,28]$. The trials are also similar in terms of the patient population, exclusion criteria and baseline characteristics. The sex balance was slightly better in the SQ ragweed SLIT tablet trials, and 5\% more subjects reported a history of asthma. Both trials asked subjects to rate AR symptoms and medication use on the same scale. Symptom scores are approximately one point higher in the SQ ragweed SLIT tablet trials, indicating more severe symptoms in both treatment arms.

One difference between GT-08 and the SQ ragweed SLIT tablet trials was the specific medications available to subjects during the trials, although they are in the same drug class. In the GT-08 trial, subjects were offered symptom-relieving medications that included desloratadine, olopatadine, budesonide and prednisone to relieve residual symptoms. Subjects in the SQ ragweed SLIT tablet trials were offered loratadine, olopatadine, mometasone and prednisone. Both trials used these medications in a stepwise manner to control symptoms: first, an antihistamine, followed by an intranasal corticosteroid and then an oral corticosteroid. Asthma rescue medications were also allowed, though they were not included in the medication score. The AR medication use in both trials was rated on a 36-point scale in which each medication was weighted according to its estimated impact on allergy symptoms. Medication scores in the SQ ragweed SLIT tablet trials were lower by approximately half a point on a 36-point scale. The locations of the trial sites also differed between the two studies. The GT-08 study included sites in seven European countries, and the SQ ragweed SLIT tablet studies included sites in the USA, Canada, Hungary, 
Ukraine and Russia. Patients were exposed to differing levels of pollen across sites.

The trials also had different treatment durations. Subjects in the GT-08 trial were treated for 3 years and followed for 2 years after treatment discontinuation, whereas subjects in the SQ ragweed SLIT tablet trials were treated for an average of 52 weeks. The European Academy of Allergy and Clinical Immunology guidelines for allergy treatment recommend at least 3 years of AIT treatment to achieve a long-term treatment effect and improvement in quality of life [29]. Additional treatment and follow-up is needed to assess long-term improvement in quality of life.

\section{Conclusions}

Application of a previously developed mapping function allowed for the calculation of QALDs associated with the SQ ragweed SLIT tablet. The mapping function was developed in a previous study based on a grass pollen trial and applied in this analysis to two pooled SQ ragweed SLIT tablet trials, validating the use of the algorithm in other seasonal pollen allergies. Although there were differences in baseline characteristics and types of supplementary medications used in the trials, these differences are minor, and application of the mapping function was appropriate. The results of the mapping showed a significant QALD benefit of the SQ ragweed SLIT tablet in the pooled P05233 and P05234 trials in the treatment of ragweed pollen-induced AR.

Author Contributions KD conducted the statistical analysis and drafted the manuscript. $\mathrm{AB}$ designed the study, assisted with statistical analysis and interpretation, and contributed to the writing of the manuscript. $\mathrm{HB}$ contributed to the writing of the manuscript.

\section{Compliance with Ethical Standards}

Conflict of interest K Dick is an employee of Avalon Health Economics, which received funding from ALK. Dr Briggs is a director and shareholder of Avalon Health Economics and received compensation from ALK as a consultant for this work. He has also been contracted by Eisai, Bayer, Merck, Janssen, Novartis, Sword Health, Amgen and Daiichi Sankyo and received compensation outside of the submitted work. H. Brandi is an employee of ALK.

Funding This study was funded by ALK.

Statement of human rights All procedures performed in studies involving human participants were conducted in accordance with good clinical practice and with the internal standard operating procedures of Schering-Plough Research Institute.

Welfare of animals This article does not contain any studies with animals performed by any of the authors.
Informed consent Informed consent was obtained from all individual participants included in the study.

Data availability The clinical trial data that support the findings of this study are proprietary to ALK and therefore cannot be made publicly available.

Open Access This article is licensed under a Creative Commons Attribution-NonCommercial 4.0 International License, which permits any non-commercial use, sharing, adaptation, distribution and reproduction in any medium or format, as long as you give appropriate credit to the original author(s) and the source, provide a link to the Creative Commons licence, and indicate if changes were made. The images or other third party material in this article are included in the article's Creative Commons licence, unless indicated otherwise in a credit line to the material. If material is not included in the article's Creative Commons licence and your intended use is not permitted by statutory regulation or exceeds the permitted use, you will need to obtain permission directly from the copyright holder.To view a copy of this licence, visit http://creativecommons.org/licenses/by-nc/4.0/.

\section{References}

1. Chen KW, et al. Ragweed Pollen Allergy: burden, Characteristics, and Management of an Imported Allergen Source in Europe. Int Arch Allergy Immunol. 2018;176(3-4):163-80.

2. Salo PM, et al. Allergy-related outcomes in relation to serum IgE: results from the National Health and Nutrition Examination Survey 2005-2006. J Allergy Clin Immunol. 2011;127(5):1226-35 (e7).

3. Smith $\mathrm{M}$, et al. Common ragweed: a threat to environmental health in Europe. Environ Int. 2013;61:115-26.

4. Burbach GJ, et al. GA(2)LEN skin test study II: clinical relevance of inhalant allergen sensitizations in Europe. Allergy. 2009;64(10):1507-15.

5. Valovirta E, Myrseth SE, Palkonen S. The voice of the patients: allergic rhinitis is not a trivial disease. Curr Opin Allergy Clin Immunol. 2008;8(1):1-9.

6. Hoehle LP, et al. Association between symptoms of allergic rhinitis with decreased general health-related quality of life. Am J Rhinol Allergy. 2017;31(4):235-9.

7. Linneberg A, et al. Burden of allergic respiratory disease: a systematic review. Clin Mol Allergy. 2016;14:12.

8. Pitt $\mathrm{AD}$, et al. Economic and quality-of-life impact of seasonal allergic conjunctivitis in Oxfordshire. Ophthalmic Epidemiol. 2004;11(1):17-33.

9. Larsen JN, Broge L, Jacobi H. Allergy immunotherapy: the future of allergy treatment. Drug Discov Today. 2016;21(1):26-37.

10. Fiocchi A, Fox AT. Preventing progression of allergic rhinitis: the role of specific immunotherapy. Arch Dis Child Educ Pract Ed. 2011;96(3):91-100.

11. Biedermann T, et al. The SQ tree SLIT-tablet is highly effective and well tolerated: results from a randomized, double-blind, placebo-controlled phase III trial. J Allergy Clin Immunol. 2019;143(3):1058-66.

12. Dhami $\mathrm{S}$, et al. Allergen immunotherapy for allergic rhinoconjunctivitis: a systematic review and meta-analysis. Allergy. 2017;72(11):1597-631.

13. Ronborg SM, et al. Budget impact analysis of two immunotherapy products for treatment of grass pollen-induced allergic rhinoconjunctivitis. Clinicoecon Outcomes Res. 2012;4:253-60. 
14. Wolowacz SE, et al. Estimating health-state utility for economic models in clinical studies: an ISPOR Good Research Practices Task Force Report. Value Health. 2016;19(6):704-19.

15. Versteegh MM, et al. Condition-specific preference-based measures: benefit or burden? Value Health. 2012;15(3):504-13.

16. Wailoo AJ, et al. Mapping to estimate health-state utility from non-preference-based outcome measures: an ISPOR Good Practices for Outcomes Research Task Force Report. Value Health. 2017;20(1):18-27.

17. Brazier JE, et al. A review of studies mapping (or cross walking) non-preference based measures of health to generic preferencebased measures. Eur J Health Econ. 2010;11(2):215-25.

18. Dick K, et al. A quality of life mapping function developed from a grass pollen sublingual immunotherapy trial to a tree pollen sublingual immunotherapy trial. J Med Econ. 2019;23(1):64-9.

19. Durham SR, et al. SQ-standardized sublingual grass immunotherapy: confirmation of disease modification 2 years after 3 years of treatment in a randomized trial. J Allergy Clin Immunol. 2012;129(3):717-25 (e5).

20. Calderón M, Brandt T. Treatment of grass pollen allergy: focus on a standardized grass allergen extract-Grazax ${ }^{\circledR}$. Ther Clin Risk Manag. 2008;4(6):1255-60.

21. Kalantari A, Rezaie SR. Challenging the 1-h sepsis bundle. West J Emerg Med. 2019;20(2):185-90.
22. Dolan P. Modeling valuations for EuroQol health states. Med Care. 1997;35(11):1095-108.

23. Juniper EF, Guyatt GH. Development and testing of a new measure of health status for clinical trials in rhinoconjunctivitis. Clin Exp Allergy. 1991;21(1):77-83.

24. Nolte H, et al. Randomized controlled trial of ragweed allergy immunotherapy tablet efficacy and safety in North American adults. Ann Allergy Asthma Immunol. 2013;110(6):450-56 (e4).

25. Creticos PS, et al. Randomized controlled trial of a ragweed allergy immunotherapy tablet in North American and European adults. J Allergy Clin Immunol. 2013;131(5):1342-9 (e6).

26. Crump RT, et al. Establishing utility values for the 22-item Sino-Nasal Outcome Test (SNOT-22) using a crosswalk to the EuroQol-five-dimensional questionnaire-three-level version (EQ5D-3L). Int Forum Allergy Rhinol. 2017;7(5):480-7.

27. Gray LA, Alava MH, Wailoo AJ. Development of methods for the mapping of utilities using mixture models: mapping the AQLQ-S to the EQ-5D-5L and the HUI3 in patients with asthma. Value Health. 2018;21(6):748-57.

28. Bauchau V, Durham SR. Prevalence and rate of diagnosis of allergic rhinitis in Europe. Eur Respir J. 2004;24(5):758-64.

29. Muraro A, et al. EAACI guidelines on allergen immunotherapy: executive statement. Allergy. 2018;73(4):739-43. 